\title{
Prevention and Treatment of SARS-CoV2 Infection in People Living with HIV: The Need for Specific Data
}

\author{
Natalia A. Díaz · Rosa de Miguel · Fernando Agüero · Omar Sued · \\ José R. Arribas · Juan Ambrosioni (1) · the Hospital Clinic COVID-19 in HIV Investigators
}

Received: October 1, 2021 / Accepted: October 5, 2021 / Published online: October 28, 2021

(C) The Author(s) 2021

\section{ABSTRACT}

The HIV pandemic has led to close to 40 million people living with HIV (PLWH) worldwide. To date, SARS-CoV2 has affected $>220$ million people, and unprecedented global efforts have resulted in almost 6000 million doses of SARS-

Natalia A. Díaz and Rosa de Miguel contributed equally to and are co-first authors of this manuscript.

Members of the Study Group are listed in the appendix.

Supplementary Information The online version contains supplementary material available at https:// doi.org/10.1007/s40121-021-00547-y.

N. A. Díaz

Infectious Diseases Service, Hospital Cuenca Alta, Cañuelas, Argentina

R. de Miguel · J. R. Arribas

Infectious Diseases Unit, Hospital Universitario La Paz, Madrid, Spain

\section{F. Agüero}

Preventive Medicine Service, Hospital Universitario Bellvitge, Barcelona, Spain

O. Sued

Fundación Huésped, Buenos Aires, Argentina

J. Ambrosioni $(\bowtie)$

HIV Unit and Infectious Diseases Service, Hospital Clinic-IDIBAPS, Villarroel 170, 08036 Barcelona, Spain

e-mail: ambrosioni@clinic.cat;

jambrosioni@intramed.net
CoV2 vaccines being administered. Although several specific COVID-19 antiviral and antiinflammatory treatments and SARS-CoV2 vaccines have been approved, the data available to support their use in specific populations such as PLWH remain limited. PLWH includes a range of individuals from practically unaffected immunity to severely immunocompromised individuals, and preventive and therapeutic interventions should be tailored for these subgroups . However, in most randomized clinical trials regarding antivirals, immunomodulators and vaccines for COVID-19, PLWH have been excluded or only enrolled in small numbers leading to a paucity of data. We briefly discuss the current evidence for prevention and treatment of COVID-19 in PLWH and identify key areas where more information is required.

Keywords: COVID-19; HIV; HIV infection; PLWH; Prevention; SARS-CoV2; SARS-CoV2 vaccines; Treatment 


\section{Key Summary Points}

Specific data on preventive measures and therapies for COVID-19 in people living with HIV (PLWH) remain extremely limited

PLWH should be prioritized for vaccination especially those with low CD4 + T-cell counts

There is insufficient evidence to select one type of vaccine for PLWH over another. RNA-based vaccines may be preferable on theoretical grounds

Vaccine responses are expected to be lower than in the general population especially in those with low CD4 T-cell counts

There is not conclusive evidence of useful efficacy of any antiretroviral drug for treatment or prevention of SARS-CoV2; studies are ongoing

Management of PLWH with COVID-19 should follow recommendations for the general population considering specific issues such as drug-drug interactions and overlapped toxicities with antiretroviral drugs

The COVID-19 research agenda should include trials in specific populations such as PLWH

\section{INTRODUCTION}

Currently, there are nearly 40 million people living with HIV (PLWH). Of them, 12.6 million PLWH are still not receiving antiretroviral therapy (ART), and the attributable global mortality due to HIV was still 690,000 deaths in 2019 [1].

SARS-CoV2 has caused 225 million cases and nearly 5 million deaths, according to a Johns Hopkins University tool (https://coronavirus. jhu.edu/map.html. Accessed 19 Sept 2021).
Prevalence of infection is evolving and depends on location, time, and transmission patterns. A recent meta-analysis of 14 studies including 7700 PLWH reported a prevalence of $0.77 \%$ [95\% confidence interval (CI) 0.39-1.51] and a mortality rate of $8.8 \%$ (95\% CI 5.8-13.2) [2]. The actual prevalence could be much higher because of the limited number of studies from low- and middle-income countries, where access to diagnosis for both diseases is limited and HIV prevalence is high. A systematic review that included 4735 PLWH and 172,451 controls suggests no impact of HIV on mortality [RR 0.99 (95\% CI 0.82-1.19)] [3] but this contrasts with another recent review reporting a two times increased risk of COVID-19-related death among PLWH [4].

The pandemic can also have an effect on many of the challenges faced by PLWH, such as mental health problems, substance abuse, poverty, lack of family support, and stigma, which exacerbates morbidity and mortality and increases the likelihood of adverse outcomes [9].

Several therapies have shown some efficacy for COVID-19, and several SARS-CoV2 vaccines have been preliminarily approved by different organizations. Prevention and treatment of COVID-19 in PLWH will depend on the results of studies showing the efficacy of interventions in this specific population, availability, national policies and prioritization that will result in real access and coverage. However, so far much of the data are limited.

We summarize the status of vaccines and other preventive strategies and therapeutic approaches for COVID-19 in PLWH.

This article is based on previously conducted studies and does not contain any new studies with human participants or animals performed by any of the authors.

\section{PREVENTION OF SARS-COV2 INFECTION IN PLWH}

Social distancing and consultation modalities such as tele-health have been revealed to be very useful, particularly for PLWH, to reduce exposure to the hospital environment and 
decrease COVID-19 cases. However, PLWH have disproportionally suffered from isolation, depression and other psychosocial issues during pandemic lockdowns. In addition, complete lockdowns may lead to ART supply discontinuations for PLWH. Thus, these preventive measures should be applied considering the potential negative consequences in this group [5].

\section{OVERVIEW OF CURRENT AVAILABLE SARS-COV2 VACCINES}

A number of vaccines against COVID-19 have been rapidly developed, and it is expected that their expanded access will help to curb the global pandemic [6]. Vaccines were initially allocated to high-priority groups such as essential frontline workers, the elderly and persons with high risk medical conditions $[7,8]$. In a joint statement, several medical national HIV societies and the European AIDS Clinical Society proposed that PLWH with low CD4 counts $(<350 / \mu \mathrm{l})$, detectable viraemia and comorbidities should be prioritized for COVID-19 vaccination. However, the same statement acknowledges that the extent to which PLWH should be prioritized, over other high-risk persons, is uncertain, which probably reflects the current heterogeneous strategies for PLWH vaccination across Europe [9]. Given that the World Health Organization's Global Clinical Platform for COVID-19 study has suggested a poor COVID-19 clinical outcome in PLWH, this organization also recommends PLWH as a priority group for vaccination (https://www.who. int/publications/i/item/WHO-2019-nCoV-

Clinical-HIV-2021.1). In this platform, however, most of the included PLWH were from South Africa, limiting the generalization of the recommendation. Another recent study also suggests a poor outcome in PLWH with CD4 + T-cell count $<200$ cells $/ \mathrm{mm}^{3}$, supporting the WHO recommendation for vaccination priority in PLWH [10]. In addition, immunocompromised PLWH may benefit from additional doses of vaccines, as is recommended for other diseases such as HBV or yellow fever [11].

\section{ATTITUDES TOWARD COVID-19 VACCINE IN PLWH}

There are still very few data on attitudes toward COVID-19 vaccine in PLWH. A global multicountry online survey, disseminated via social media and associations related to PLWH, showed that $76.1 \%$ of 247 respondents would be willing to receive the vaccine. In this small survey, there were no differences in vaccine acceptability rate between low- and high-income countries [12]. A French single-centre online survey on COVID-19 vaccine acceptability revealed that around one third of the participants would hesitate to receive a coronavirus vaccine. Reasons listed for vaccine hesitancy included general vaccine refusal, fear of adverse reactions, and assumed COVID-19 immunity. Those in favour expressed concerns about their health-including chronic diseaseas reasons for vaccine acceptability [13-16].

\section{COVID-19 VACCINE OUTCOMES IN PLWH}

Although the number of PLWH participating in trials that evaluated COVID-19 vaccines is very limited, the World Health Organization, UNAIDS and clinical societies express confidence in vaccine safety and effectiveness in this key population $[9,17,18]$. BNT162b2 (Pfizer) mRNA vaccine phase $2 / 3$ trial included 196 PLWH (0.5\% of total participants), but the efficacy and safety data of the vaccine were not reported for this population [19]. mRNA-1273 (Moderna) trial included 176 PLWH $(0.6 \%$ of total participants) of whom 90 received the vaccine and none had COVID-19 infection after receiving the two scheduled doses $(100 \%$ vaccine efficacy) $[20,21]$. Ad26.COV2.S adenovirus 26 vector vaccine (Janssen/Johnson \& Johnson COVID-19 vaccine) trial has included what, to date, is the largest number of PLWH: 467 wellcontrolled PLWH (virologically suppressed, CD4 cell count $\geq 300$ cells $/ \mu$ l on stable ART) received a single dose of the vaccine and 498 received placebo. At 28 days post-vaccination, two persons from the vaccine group and four 
from the placebo group had moderate to severe/critical COVID-19 (vaccine efficacy 47.5\%, confidence interval [CI] - 266.0-95.3\%), without any significant differences in safety [22].

In South Africa, where the Beta variant virus (B.1.351) was predominant at the time of the study, the phase 2a-b trial evaluating the NVXCoV2373 (Novavax) vaccine included medically stable PLWH $(6 \%$ of the total COVID-19 seronegative sample) randomized to receive two doses of the recombinant protein vaccine or placebo. In PLWH, symptomatic COVID-19 infection (a minimum of 7 days after second dose) occurred among COVID-19-seronegative participants in $4 / 76$ of those receiving the vaccine and 2/72 from the placebo group, without any case reported in COVID19-seropositive participants from either intervention group. This trial was not powered to detect efficacy in PLWH, and authors advocate for a cautious interpretation of the results of this study considering the limited sample of HIV-infected participants [23].

Gam-COVID-Vac/Sputnik V (Gamaleya Institute), WIV04 and HB02 (Sinopharm) and CoronaVac (Sinovac) have excluded PLWH from their pivotal trials [24-26].

A sub-study in PLWH within the COV002 trial for the ChAdOx1 nCoV-19/AZD1222 (Astra Zeneca) vaccine [27] analysed the immunogenicity and safety of two doses of this vaccine in 54 participants from two UK clinics under ART with controlled viremia and CD4 $>350$ cells/per $\mu \mathrm{l}$. Compared to HIV-uninfected persons of the same age, there were no differences in humoral and cell-mediated immune response after 56 days of follow-up [28]. An interim analysis of the COV005 trial in South Africa for the same vaccine showed that two doses were well tolerated with similar neutralizing response patterns in PLWH and HIV-negative participants [29]. A prospective study of the BNT162b2 (Pfizer) vaccine conducted in 143 virologically suppressed PLWH with high CD4 T-cell count found that 97\% developed anti-RBD-IgG in this group, while $98.9 \%$ did in the control group. Neutralizing activity was similar in both groups [30]. In a small study (12 PLWH vs. 17 controls) of the same vaccine robust immune responses were observed in PLWH, comparable to responses in healthy donors [31]. Following natural SARS-CoV2 infection, immune responses in PLWH were similar to those of immunocompetent convalescent patients developing similar COVID-19 disease severity in another recent study [32].

There are other studies that will likely bring light to our current areas of uncertainty for COVID-19 vaccines in PLWH: there is an ongoing trial with NVX-CoV2373 (Novavax) including a cohort of PLWH to specifically study the immunogenicity of the vaccine (NCT04533399) and the CoronaVac (Sinovac) vaccine will be evaluated in a Brazilian trial including PLWH (NCT04754698). In Argentina, a Phase IIB study will evaluate immunogenicity of the CanSino Adenovirus 5 vaccine in PLWH. Also, two European cohorts will investigate the immunogenicity, safety and efficacy of COVID19 vaccines in PLWH (NCT04844489, NCT04805125). Of note, one matched casecontrol observational trial found that PLWH had lower IgG SARS-COV2 concentrations after the infection compared to non-HIV participants, which questions the immune response to COVID-19 of PLWH, which may also affect vaccine immunogenicity and consequently vaccine efficacy [33]. As none of the approved vaccines is a live-attenuated vaccine, no safety concerns should be expected, although immunogenicity could potentially be lower in immunosuppressed PLWH. PLWH can also lose antibodies more rapidly than uninfected individuals, and more studies can shed light on the potential impact of additional vaccine doses in this population [34]. Surrogate measures of immune response and protection following SARS-CoV2 vaccination are still poorly established in the general population and thus also unknown in PLWH. A summary of available data for PLWH from SARS-CoV2 vaccine trials is shown in Table 1.

\section{OTHER COVID-19 PREVENTION MEASURES IN PLWH}

Some studies are examining the potential activity of some antiretrovirals in preventing COVID-19 [35]. A Spanish cohort study found 
Table 1 Results from vaccines approved by WHO and/or with evidence from phase III clinical trials reporting data for PLWH

\begin{tabular}{|c|c|c|c|c|c|}
\hline Vaccine (company) & Type & $\begin{array}{l}\text { Dose } \\
\text { number/ } \\
\text { interval }\end{array}$ & $\begin{array}{l}\text { HIV } \\
\text { participants } \\
\text { number }\end{array}$ & End point & Efficacy in PLWH \\
\hline $\begin{array}{l}\text { BNT162b2 (Pfizer- } \\
\text { BioNTech) (16) }\end{array}$ & $\begin{array}{l}\text { mRNA } \\
\text { vaccine }\end{array}$ & $\begin{array}{l}2 \text { doses/ } \\
3 \text { weeks }\end{array}$ & 196 & $\begin{array}{r}\text { COVID-19 } \\
\text { ocurrence }\end{array}$ & NR \\
\hline $\begin{array}{l}\text { mRNA-1273 } \\
\qquad \text { (Moderna) (17) }\end{array}$ & $\begin{array}{l}\text { mRNA } \\
\text { vaccine }\end{array}$ & $\begin{array}{l}2 \text { doses/ } \\
4 \text { weeks }\end{array}$ & $\begin{array}{l}176(90 \\
\text { vaccine })\end{array}$ & $\begin{array}{l}\text { COVID-19 } \\
\text { occurrence }\end{array}$ & $100 \%$ \\
\hline $\begin{array}{l}\text { Ad26.COV2.S } \\
\text { (Janssen/Johnson } \\
\text { \& Johnson) (19) }\end{array}$ & $\begin{array}{l}\text { Adenovirus } \\
26 \text { vector }\end{array}$ & Single dose & $\begin{array}{l}965(467 \\
\text { vaccine })\end{array}$ & $\begin{array}{l}\text { Moderate to } \\
\text { severe/critical } \\
\text { COVID-19 } \\
\text { ocurrence }\end{array}$ & $47.5 \%(\mathrm{CI}-266.0-95.3 \%)$ \\
\hline $\begin{array}{l}\text { ChAdOx1 nCoV- } \\
\text { 19/AZD1222 } \\
\text { (University of } \\
\text { Oxford/ } \\
\text { AstraZeneca/ } \\
\text { Serum Institute of } \\
\text { India), COV002 } \\
\text { sub-study (25) }\end{array}$ & $\begin{array}{l}\text { Chimpanzee } \\
\text { adenovirus } \\
\text { vector }\end{array}$ & $\begin{array}{l}2 \text { doses/ } \\
4-12 \text { weeks } \\
\text { (4-6 weeks } \\
\text { for PLWH) }\end{array}$ & 54 & $\begin{array}{l}\text { Reactogenicity } \\
\text { compared to } \\
\text { non-HIV }\end{array}$ & $\begin{array}{l}\text { No difference in magnitude or } \\
\text { persistence of SARS-CoV-2 } \\
\text { spike-specific humoral or } \\
\text { cellular responses }\end{array}$ \\
\hline $\begin{array}{l}\text { NVX-CoV2373 } \\
\text { (Novavax) (20) }\end{array}$ & $\begin{array}{l}\text { Recombinant } \\
\text { protein }\end{array}$ & $\begin{array}{l}2 \text { doses/ } \\
3 \text { weeks }\end{array}$ & $\begin{array}{l}\text { Full number } \\
\text { NR }\end{array}$ & $\begin{array}{l}\text { COVID-19 } \\
\text { occurrence }\end{array}$ & NR \\
\hline
\end{tabular}

$C I$ confidence interval, $N R$ not reported

that those receiving TDF/FTC had a reduced risk of COVID-19 diagnosis and hospitalization [36]. In line with these results, a South African cohort study also found reduced COVID-19 mortality among PLWH receiving TDF/FTC compared to abacavir/zidovudine [37]. However, the COVIDHIVPrEP study retrospectively analyzed the attack rate of COVID-19 infection among PLWH and receiving PrEP and found no significant differences compared to the general population, and a recent French study found similar prevalence of SARS-CoV-2 IgG in PrEP users and in a matched cohort in the Paris region after the COVID-19 lockdown, suggesting that TDF/FTC has no role in reducing SARSCoV- 2 acquisition [38-41].

Protease inhibitors (PIs) were widely prescribed in the initial stages of the pandemic.
Current guidelines do not recommend PIs for COVID-19 treatment [42], but a prospective cohort study in France will compare incidence of COVID-19 in PLWH receiving PIs compared to other ART (COVIP, NCT04357639). COVID19 protective effect of TDF or PI in PLWH remains inconclusive [43], and several clinical HIV societies have expressed that changing ART for this reason is unjustified [9].

Few other trials are evaluating preventive drug strategies for PLWH in particular. Nitazoxanide, an antiprotozoal drug with in vitro activity against SARS-CoV-2, is currently being investigated in a randomized trial conducted in South Africa aimed at PLWH and adults at high risk for severe disease (NCT04523090).

Finally, there is a scarcity of studies analyzing whether in PLWH there are any differences 
in the effectiveness of other preventive measures for COVID-19 such as lockdowns, social distancing and face masking. However, especially in resource-limited settings PLWH may be at higher risk of food insecurity, domestic violence, mental health disease and loss of access to care associated with COVID-19 lockdowns $[44,45]$, which highlights the importance of ensuring continuous medical and social support even when a pandemic is ongoing in vulnerable collectives [46].

\section{TREATMENT OF SARS-COV2 INFECTION IN PLWH}

\section{Therapeutic Agents}

Several pharmacological therapies have shown efficacy for COVID-19 and many are under evaluation in ongoing clinical trials. Current available clinical practice guidelines offer several recommendations on pharmacological management, based on emerging evidence. However, little is known about COVID-19 treatment in PLWH [5]. Nevertheless, many of the clinical trials of approved COVID-19 therapies excluded PLWH and, when included, no outcomes were reported in this population. If available information for SARS-CoV2 prevention in PLWH is limited, this is even more remarkable for SARS-CoV2 treatment, where there are almost no available data on this population.

In Supplemental Table 1 we have summarized the available information on the main antiviral therapies (e.g., remdesivir or baricitinib, among others) [51-56], immunomodulators (e.g., steroids or specific IL blockers) [57-73] and anti-SARS-CoV-2 antibody products $[50,74-84]$. As shown in Suppl. table 1, the inclusion of PLWH was extremely low, or even not reported. While it is expected that in PLWH on ART and with high CD4 T-cell count treatment responses should be similar to those of the general population, this may not be necessarily the case for PLWH with more advanced disease. In these patients, duration and/or doses of specific therapies may differ. In addition, specific issues for this population should be considered as differential diagnosis and co-infections which may require tailored specific approaches.

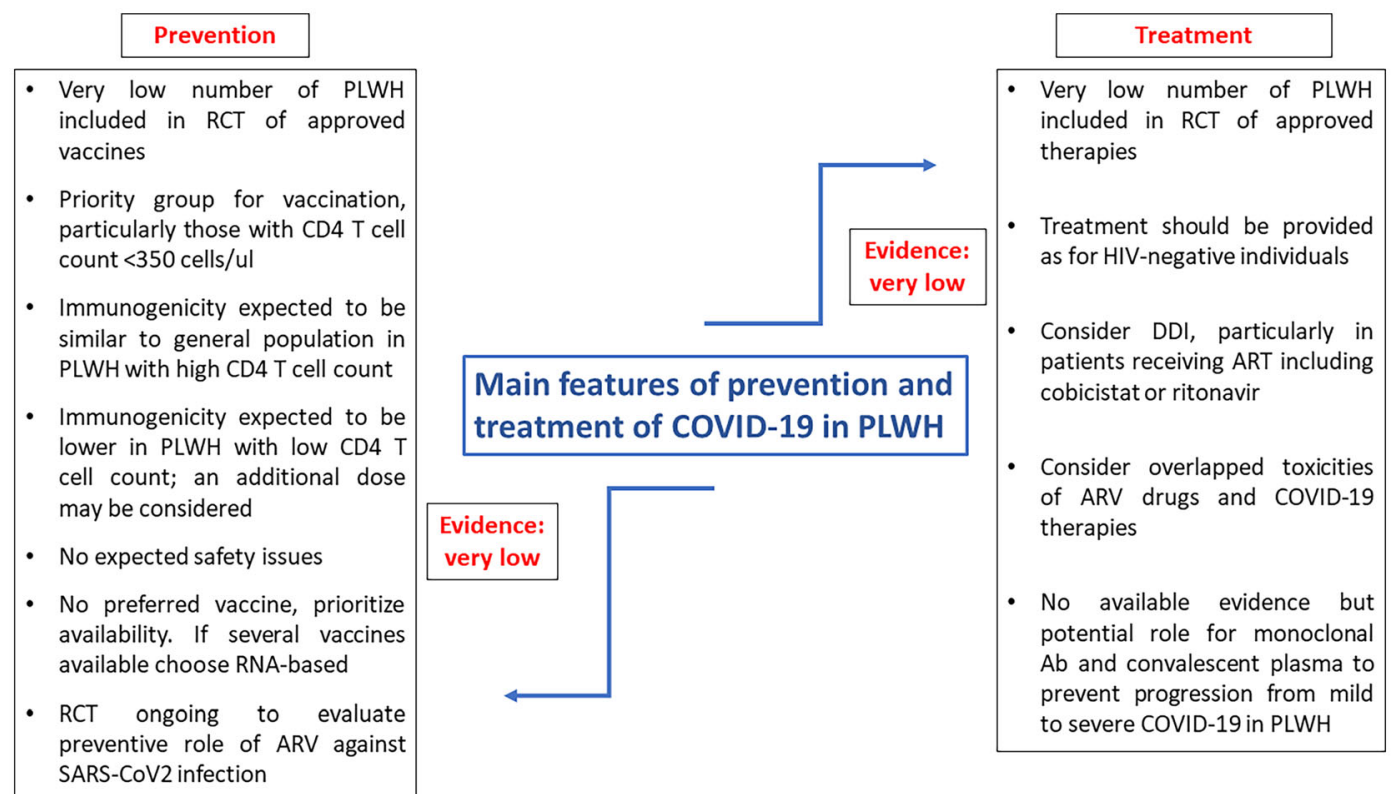

Fig. 1 Main features of prevention and treatment of COVID-19 in people living with HIV (PLWH) 


\section{DISCUSSION}

As previously shown, the inclusion of PLWH in RCT has been very low for vaccines and treatments and most of the recommendations adopted by scientific societies remain theoretical for this population, until more data become available. We have appraised the available evidence in this commentary article and the main features are highlighted in Fig. 1 .

Social distancing and lockdowns have been shown to decrease SARS-CoV2 transmission during the waves of the pandemic. Their psychosocial consequences, however, may be serious in PLWH and may risk ART supply and services disruptions [5]. Vaccination is recommended for all PLWH, despite low CD4 cell count, although observational studies showed lower response in this population [47]. Different vaccination strategies should be considered to achieve and maintain long-term immunity. Additional booster doses of mRNA vaccines are under consideration in immunocompromised patients as they could increase immunogenicity and have demonstrated to be safe in small RCT [48]. This strategy has been practiced with other vaccines for PLWH, e.g., booster doses or increased doses of hepatitis $B$ virus vaccine in patients with poor response [49] and a booster dose of yellow fever vaccine for specific high risk populations has also been recommended by the CDC [11]. This strategy is particularly relevant for the Delta variant where neutralizing titres reached by the vaccines need to be high. Data so far in the early follow-up indicate a similar immune response to COVID-19 vaccination as the general population in virologically suppressed PLWH in good immunological condition $[28,31]$. To date, there is not a preferred vaccine for PLWH. It would be reasonable to prioritize vaccines with the highest response rates (RNA-based) when possible, but no delay in vaccination is recommended and PLWH should get vaccinated as soon as possible with the available vaccines, starting with those with low CD4 T-cell count. No safety concerns should be expected since none of the COVID-19 vaccines is an attenuated-virus vaccine and they can be given to people with any level of immunity. Thus, the benefits of vaccination in PLWH outweigh the risks.

Regarding pharmacological prevention measures, to date, there is no evidence to support any ARV for prevention of COVID-19, and switching ART for this reason is unjustified, but ongoing RCT will probably definitively clarify this. Available evidence in PLWH is scarce, as RCTs have not included PLWH and, when included, no outcomes were reported in this patient group. However, the high prevalence of comorbidities in PLWH should be kept in mind, such as cardiovascular disease, chronic lung disease, diabetes and obesity, which increase their risk, as in the general population. In the presence of comorbidities and/or in PLWH not on ART or with low CD4 cell count, poorer responses to SARS-CoV2 therapies are expected compared to the general population. In addition, despite antiviral therapy (such as remdesivir), protracted disease and longer SARS-CoV2 replication could be expected [5].

Most COVID-19 studies in PLWH have been conducted in high-income countries where a high proportion of PLWH is successfully treated and virologically suppressed; data in PLWH not receiving antiretroviral therapy or with impaired cell immunity $(<350$, and particularly $<200$ CD4 T-cells) are scarce [30, 70]. It has to be assumed that such patients are at highest risk for severe COVID-19 and poor outcomes $[7,70]$. Thus, they should have a tailored approach: clinicians should beware of coinfections such as tuberculosis, pneumocystis or strongyloides and be cautious when prescribing steroids, tocilizumab or other immunomodulators, as they can exacerbate HIV-related immune suppression. This patient group should also be prioritized for vaccination (despite probably poor responses).

Potential drug-drug interactions (DDI) must be considered when managing PLWH coinfected with COVID-19, especially in those patients receiving boosted ARVs (with cobicistat or ritonavir), as these drugs are CYP $3 \mathrm{~A}$ substrate and have a high potential for pharmacokinetic interaction with other drugs of hepatic metabolism such as steroids, although dose modifications are not required. DDIs among steroids, doravirine and rilpivirine have to be considered 
also, as steroids are moderate CYP3A4 inducers and could decrease doravirine and rilpivirine efficacy. Increasing doravirine and rilpivirine doses to $100 \mathrm{mg}$ BD and $50 \mathrm{mg}$ QD, respectively, for approximately 2 weeks should be considered after the end of dexamethasone or switching to an alternative ARV in the case of rilpivirine (https://www.covid19-druginteractions.org).

DDIs are not relevant with remdesivir.

Potential overlapping toxicities between ARVs and COVID-19 treatment drugs must be also monitored. Liver injury has been reported with tocilizumab and remdesivir and could enhance hepatotoxicity of certain ARVs such as PIs, cobicistat-boosted ARVs and non-nucleoside reverse transcriptase inhibitors [71, 72]. Kidney injury has also been reported with remdesivir administration; thus, renal function must be closely monitored, especially in patients receiving nephrotoxic ARVs such as TDF [72]. Appropriate prophylaxis for opportunistic infections should be initiated when indicated.

Monoclonal antibodies and convalescent plasma seem promising in mild to moderate COVID-19 to avoid progression to severe disease in high-risk patients, including immunosuppressed individuals and especially in SARS-Cov2 seronegative patients [53]. Specific data in PLWH are not available yet but they could have a role in avoiding disease progression in patients with low CD4 T-cell count and in patients with persistent infection.

Important studies are still ongoing that will probably clarify relevant issues on prevention and treatment of COVID-19 in PLWH and will be worth reading when published. Some of them are the Novavax (NCT04533399), ChAdOx1 nCoV-19 (NCT04444674), COVIVAC-ID (NCT04844489) and COVERALL (NCT04805125) trials, which are evaluating vaccines in PLWH; the trials on monoclonal antibodies, which seem promising for the treatment of immunosuppressed COVID-19 patients, include: RECOVERY, BLAZE-1 (NCT04427501), BLAZE-4 (NCT04634409), R10933-10987-COV-2067 (NCT04425629) and COMET-ICE (NCT04545060). The results of these studies will probably clarify the landscape of COVID-19 prevention and treatment in PLWH.
In conclusion, regarding SARS-CoV2 prevention, general measures such as social distancin $g$ and lockdowns are useful to decrease transmission, but their consequences have to be balanced carefully in PLWH in terms of psychosocial consequences and risk of ART disruptions. PLWH should be prioritized for vaccination, especially those with low CD4 T-cell counts. In the small available studies, immunogenicity of vaccines seems to be comparable to that of controls, although it could be lower for the more severely immunocompromised PLWH. This could be a suitable group for administration of a third booster dose like other groups with altered immune response. If vaccine availability is lacking and the pandemic is ongoing, receiving any vaccine should be prioritized rather than awaiting results of the ongoing trials to select which would be more effective in this population; no safety concerns are expected in PLWH. Regarding treatment of SARS-COV2 infection, data for PLWH are more limited than for prevention. Waiting for specific data, COVID-19 treatment should be the same as for the general population considering the particularities of this population: potential DDIs, the specific risk of co-infections, poorer responses to therapy and outcomes in case of comorbidities and low CD4 cell count.

As the pandemic evolves, the research agenda should include studies directed to specific populations such as PLWH (among others, e.g., transplant recipients, haematology patients, etc.). Inclusion of PLWH in RCT (or studies exclusively performed in this group) is urgently needed to provide more specific data on this population.

\section{ACKNOWLEDGEMENTS}

Funding. No funding or sponsorship was received for this study or publication of this article.

Authorship. All named authors meet the International Committee of Medical Journal Editors (ICMJE) criteria for authorship for this article, take responsibility for the integrity of 
the work as a whole, and have given their approval for this version to be published.

Author Contributions. Natalia A Díaz and Juan Ambrosioni designed the first draft. Natalia A Díaz and Rosa de Miguel collected data, Natalia A Díaz, Rosa de Miguel and Omar Sued wrote the first version of the manuscript. Juan Ambrosioni, Fernando Agüero, Omar Sued and José Ramón Arribas contributed to critically revising the manuscript for corrections of all sections. All authors reviewed and accepted the final version of the manuscript.

Disclosures. Rosa de Miguel reports personal fees and non-financial support from ViiV and personal fees and non-financial support from Gilead outside the submitted work. Juan Ambrosioni has participated in advisory boards and received consulting honoraria and research grants or both from Gilead Sciences, Janssen Pharmaceuticals, ViiV Healthcare, DSMB for Grifols and HIPRA outside the submitted work. Omar Sued reports advisory fees from Novartis, ViiV and Janssen outside the submitted work. José Ramón Arribas reports advisory fees, speaker fees and grant support from ViiV, GSK, Janssen, Gilead, MSD, Alexa, Serono, Lilly and Roche outside the submitted work. Natalia A Díaz and Fernando Agüero have nothing to disclose.

Omar Sued has changed his affiliation after the completion of the manuscript. Previous affiliation during study: Fundación Huésped, Buenos Aires, Argentina. Current affiliation: Regional Advisor for Latin America and the Caribbean, HIV treatment and care for Pan American Health Organization.

Compliance with Ethics Guidelines. This article is based on previously conducted studies and does not contain any new studies with human participants or animals performed by any of the authors.

Data Availability. Data sharing is not applicable to this article as no datasets were generated or analyzed during the current study.

List of Investigators. Hospital Clinic de Barcelona COVID-19 in HIV Investigators: Juan
Ambrosioni, José L. Blanco, Lorena de la Mora, Felipe García-Alcaide, Ana González-Cordón, Alexis Inciarte, Montserrat Laguno, Lorna Leal, Esteban Martínez-Chamorro, María MartínezRebollar, José M. Miró, Jhon F. Rojas, Berta Torres, Josep Mallolas (HIV/AIDS Unit), Laia Albiac, Daiana L. Agüero, Marta Bodro, Celia Cardozo, Mariana Chumbita, Nicol García, Carolina García-Vidal, Marta M. HernándezMeneses, Sabina Herrera, Laura Linares, Antonio Moreno, Laura Morata, Jose A. MartínezMartínez, Pedro Puerta, Verónica Rico, Alex Soriano (Infectious Diseases Service), Mikel Martínez, María del Mar Mosquera, María A. Marcos, Jordi Vila (Microbiology Service), Montse Tuset, Dolors Soy (Pharmacy Department), Anna Vilella (Preventive Medicine Service), Alex Almuedo, María J. Pinazo, José Muñoz (IsGlobal).

Open Access. This article is licensed under a Creative Commons Attribution-NonCommercial 4.0 International License, which permits any non-commercial use, sharing, adaptation, distribution and reproduction in any medium or format, as long as you give appropriate credit to the original author(s) and the source, provide a link to the Creative Commons licence, and indicate if changes were made. The images or other third party material in this article are included in the article's Creative Commons licence, unless indicated otherwise in a credit line to the material. If material is not included in the article's Creative Commons licence and your intended use is not permitted by statutory regulation or exceeds the permitted use, you will need to obtain permission directly from the copyright holder. To view a copy of this licence, visit http://creativecommons.org/licenses/by$\mathrm{nc} / 4.0 /$.

\section{REFERENCES}

1. UNAIDS. UNAIDS data 2020. 2020. Available at: https://www.unaids.org/sites/default/files/media_ asset/2020_aids-data-book_en.pdf. Accessed 5 June 2021. 
2. Liang $\mathrm{M}$, Luo $\mathrm{N}$, Chen $\mathrm{M}$, et al. Prevalence and mortality due to COVID-19 in HIV co-infected population: a systematic review and meta-analysis. Infect Dis Ther. 2021;3:1-192.

3. Sarkar S, Khanna P, Singh AK. Impact of COVID-19 in patients with concurrent co-infections: a systematic review and meta-analyses. J Med Virol. 2021;93:2385-95.

4. Mellor MM, Bast AC, Jones NR, et al. Risk of adverse coronavirus disease 2019 outcomes for people living with HIV. AIDS. 2021;35:F1-10.

5. Ambrosioni J, Blanco JL, Reyes-urueña JM, et al. Review overview of SARS-CoV-2 infection in adults living with HIV. Lancet HIV. 2021;8:e294-305.

6. Rawat K, Kumari P, Saha L. COVID-19 vaccine: a recent update in pipeline vaccines, their design and development strategies. Eur J Pharmacol. 2021;892: 173751.

7. Dooling K, Marin M, Wallace M, et al. The Advisory Committee on Immunization Practices' updated interim recommendation for allocation of COVID19 vaccine-United States, December 2020. MMWR Morb Mortal Wkly Rep. 2021;69:1657-60.

8. World Health Organization. Who Sage Roadmap for Prioritizing Uses of Covid-19 Vaccines in the Context Of Limited Supply. November 2020. Available at: https://www.who.int/publications/i/ item/who-sage-roadmap-for-prioritizing-uses-ofcovid-19-vaccines-in-the-context-of-limitedsupply. Accessed 10 June 2021.

9. BHIVA, DAIG, EACS, GESIDA, Polish Scientific AIDS Society, Portuguese Association for the clinical study of AIDS (APECS). Statement on risk of COVID-19 for people living with HIV (PLWH) and SARS-CoV-2 vaccine advice for adults living with HIV. Jan 2021. Available at: https://www.bhiva.org/ joint-statement-on-risk-of-COVID-19-for-PLWHand-SARS-CoV-2-vaccine-advice. Accessed: 10 June 2021.

10. Normah D, Reyes-Ureña J, Diaz Y, et al. CD4+ T-cell count below 200 cells/mm3 is associated with worse COVID-19 outcomes among people living with HIV regardless of virological suppression. Abstract \# OALB0301. IAS 2021.

11. Staples EJ, Bocchini JA, Rubin L, Fischer M. Yellow fever vaccine booster doses: recommendations of the advisory commitee on immunization practices, 2015. MMWR Morb Mortal Wkly Rep. 2015;64: 647-50.

12. Siewe Fodjo JN, de Moura Villela EF, Villela E, Van Hees S, Vanholder P, Reyntiens P, Colebunders R. Follow-up survey of the impact of COVID-19 on people living with hiv during the second semester of the pandemic. Int J Environ Res Public Health. 2021;18:4635.

13. Vallée A, Fourn E, Majerholc C, Touche P, Zucman D. COVID-19 vaccine hesitancy among french people living with HIV. Vaccines. 2021;9(302):1-9.

14. Bogart LM, Ojikutu BO, Tyagi K, et al. COVID-19 related medical mistrust, helath impacts, and potential vaccine hesitancy and black americans living with HIV. J Acquir Immune Defic Syndr. 2021;86:200-7.

15. Jones DL, Salazar AS, Rodriguez VJ, et al. Severe acute respiratory syndrome coronavirus 2 : vaccine hesitancy among underrepresented racial and ethnic groups with HIV in Miami, Florida. Open Forum Infect Dis. 2021. https://doi.org/10.1093/ofid/ ofab154.

16. Nachega JB, Sam-Agudu NA, Mellors JW, Zumla A, Mofenson LM. Scaling up Covid-19 vaccination in Africa-lessons from the HIV pandemic. N Engl J Med. 2021;385:196-8.

17. World Health Organization (WHO). Coronavirus disease (COVID-19): COVID-19 vaccines and people living with HIV. April 2021. Available at: https:// www.who.int/news-room/q-a-detail/coronavirusdisease-(covid-19)-covid-19-vaccines-and-peopleliving-with-hiv. Accessed 8 June 2021

18. UNAIDS. COVID-19 vaccines and HIV. 2021: Available at: https://www.unaids.org/sites/default/ files/media_asset/covid19-vaccines-and-hiv_en.pdf. Accessed 8 June 2021.

19. Polack FP, Thomas SJ, Kitchin N, et al. Safety and efficacy of the BNT162b2 mRNA Covid-19 vaccine. N Engl J Med. 2020;383:2603-15.

20. Baden LR, El Sahly HM, Essink B, et al. Efficacy and safety of the mRNA-1273 SARS-CoV-2 vaccine. N Engl J Med. 2021;384:403-16.

21. FDA Vaccines and Related Biological Products Advisory Committee Meeting. FDA Briefing Document Moderna COVID-19 Vaccine. December 17, 2020;1-54.

22. WHO. Background document to the WHO Interim recommendations for use of Ad26.COV2.S (COVID19) vaccine. Available at: https://apps.who.int/iris/ handle/10665/340180. Accessed 17 March 2021.

23. Shinde V, Bhikha S, Hoosain Z, et al. Efficacy of NVX-CoV2373 Covid-19 vaccine against the B.1. 351 variant. N Engl J Med. 2021;384(20):1899-909.

24. Logunov DY, Dolzhikova IV, Shcheblyakov DV, et al. Safety and efficacy of an rAd26 and rAd5 
vector-based heterologous prime-boost COVID-19 vaccine: an interim analysis of a randomised controlled phase 3 trial in Russia. Lancet. 2021;397: 671-81.

25. Zhang Y, Zeng G, Pan H, et al. Safety, tolerability, and immunogenicity of an inactivated SARS-CoV-2 vaccine in healthy adults aged $18-59$ years: a randomised, double-blind, placebo-controlled, phase 1/2 clinical trial. Lancet Infect Dis. 2021;21:181-92.

26. Al Kaabi N, Zhang Y, Xia S, et al. Effect of 2 inactivated SARS-CoV-2 vaccines on symptomatic COVID-19 infection in adults: a randomized clinical trial. JAMA. 2021;326:35-45.

27. Voysey M, Clemens SAC, Madhi SA, et al. Safety and efficacy of the ChAdOx1 nCoV-19 vaccine (AZD1222) against SARS-CoV-2: an interim analysis of four randomised controlled trials in Brazil, South Africa, and the UK. Lancet. 2021;397:99-111.

28. Frater J, Ewer KJ, Ogbe A, et al. Safety and immunogenicity of the ChAdOx1 nCoV-19 (AZD1222) vaccine against SARS-CoV-2 in HIV infection: a single-arm substudy of a phase $2 / 3$ clinical trial. Lancet HIV. 2021;19:1-12.

29. Madhi SA, Koen AL, Izu A, et al. Safety and immunogenicity of the ChAdOx1 nCoV-19 (AZD1222) vaccine against SARS-CoV-2 in people living with and without HIV in South Africa: an interim analysis of a randomised, double-blind, placebo-controlled, phase $1 \mathrm{~B} / 2 \mathrm{~A}$ trial. Lancet HIV. 2021;8:e568-80.

30. Levy I, Wieder-Finesod A, Litchevsky V, et al. Immunogenicity and safety of the BNT162b2 mRNA COVID-19 vaccine in people living with HIV-1. Clin Microbiol Infect. 2021. https://doi.org/ 10.1016/j.cmi.2021.07.031.

31. Woldemeskel BA, Karaba AH, Garliss CC, et al. The BNT162b2 mRNA vaccine elicits robust humoral and cellular immune responses in people living with HIV. Clin Infect Dis. 2021. https://doi.org/10. 1093/cid/ciab648.

32. Donadeu L, Tiraboschi J, Favá A, Scévola S, Podzamczer D, Bestard O. Robust SARS-CoV-2specific serological and functional T-cell immunity in PLWHIV. Abstract \# OAB0101. IAS 2021.

33. Spinelli MA, Lynch KL, Yun C, et al. SARS-CoV-2 seroprevalence, and IgG concentration and pseudovirus neutralising antibody titres after infection, compared by HIV status: a matched case-control observational study. Lancet HIV. 2021;3018:1-8.

34. Touizer E, Alrubayyi A, Rees-Spear C, et al. Failure to seroconvert after two doses of BNT162b2 SARS-
CoV-2 vaccine in a patient with uncontrolled HIV. Lancet HIV. 2021;8:e317-8.

35. Alavian G, Kolahdouzan K, Mortezazadeh M, Torabi ZS. Antiretrovirals for prophylaxis against COVID19: a comprehensive literature review. J Clin Pharmacol. 2021;61:581-90.

36. del Amo J, Polo R, Moreno S, et al. Antiretrovirals and risk of COVID-19 diagnosis and hospitalization in HIV-positive persons. Epidemiology. 2020;31: e49-51.

37. Boulle A, Davies M, Hussey H, et al. Risk factors for coronavirus disease 2019 (COVID-19) death in a population cohort study from the Western Cape Province, South Africa. Clin Infect Dis. 2021;73: e2005-15.

38. Charre C, Icard V, Pradat P, et al. Coronavirus disease 2019 attack rate in HIV-infected patients and in preexposure prophylaxis users. AIDS. 2020;34: $1765-70$.

39. Parienti J-J, Prazuck T, Peyro-Saint-Paul L, et al. Effect of tenofovir disoproxil fumarate and emtricitabine on nasopharyngeal SARS-CoV-2 viral load burden amongst outpatients with COVID-19: a pilot, randomized, open-label phase 2 trial. EClinicalMedicine. 2021;38:100993.

40. Berenguer J, Díez C, Martín-Vicente $M$, et al. Prevalence and factors associated with SARS-CoV-2 seropositivity in the Spanish HIV Research Network Cohort. Clin Microbiol Infect. 2021. https://doi. org/10.1016/j.cmi.2021.06.023.

41. Delaugerre MC, Assoumou L, Maylin S, et al. SARS CoV-2 seroprevalence among HIV-negative participants using tenofovir/emtricitabine-based PrEP in 2020 - a sub-study of PREVENIR-ANRS and SAPRISSero. Abstract \# OAC0201. IAS 2021.

42. Rochwerg B, Siemieniuk RA, Agoritsas T, et al. A living WHO guideline on drugs for covid-19. BMJ. 2020;370:m3379.

43. Ssentongo P, Heilbrunn ES, Ssentongo AE, et al. Epidemiology and outcomes of COVID-19 in HIVinfected individuals: a systematic review and metaanalysis. Sci Rep. 2021;11:6283.

44. Okumu M, Nyoni T, Byansi W. Alleviating psychological distress and promoting mental wellbeing among adolescents living with HIV in sub-Saharan Africa, during and after COVID-19. Glob Public Health. 2021;16:964-73.

45. Cooley SA, Nelson B, Doyle J, Rosenow A, Ances BM. Collateral damage: impact of SARS-CoV-2 pandemic in people living with HIV. J Neurovirol. 2021;27:168-70. 
46. Waterfield KC, Shah GH, Etheredge GD, Ikhile O. Consequences of COVID-19 crisis for persons with HIV: the impact of social determinants of health. BMC Public Health. 2021;21:1-7.

47. Ruddy JA, Boyarsky BJ, Werbel WA, et al. Safety and antibody response to the first dose of severe acute respiratory syndrome coronavirus 2 messenger RNA vaccine in persons with HIV. AIDS. 2021;35: 1872-4.

48. Hall VG, Ferreira VH, Terrance K, et al. Randomized trial of a third dose of mRNA-1273 vaccine in transplant recipients. New Engl J Med. 2021;385: 1244-6.

49. Farooq PD, Sherman KE. Hepatitis B vaccination and waning hepatitis B immunity in persons living with HIV. Curr HIV/AIDS Rep. 2019;16:395-403.

50. Dandachi D, Geiger G, Montgomery MW, et al. Characteristics, comorbidities, and outcomes in a multicenter registry of patients with human immunodeficiency virus and coronavirus disease 2019. Clin Infect Dis. 2020;65212:1-9.

51. Gatti M, Fusaroli M, Caraceni P, Poluzzi E, De Ponti F, Raschi E. Serious adverse events with tocilizumab: pharmacovigilance as an aid to prioritize monitoring in COVID-19. Br J Clin Pharmacol. 2021;87:1533-40.

52. Charan J, Kaur RJ, Bhardwaj P, et al. Rapid review of suspected adverse drug events due to remdesivir in the WHO database; findings and implications. Expert Rev Clin Pharmacol. 2021;14:95-103.

53. Food and Drug Administration. Fact Sheet for Health Care Providers: emergency use authorization (EUA) of REGEN-COV (casirivimab with imdevimab) 2021; Available from: https://www.fda. gov/media/145611/download. Accessed 7 June 2020.

54. Wang Y, Zhang D, Du G, et al. Remdesivir in adults with severe COVID-19: a randomised, double-blind, placebo-controlled, multicentre trial. Lancet. 2020;395:1569-78.

55. Spinner CD, Gottlieb RL, Criner GJ, et al. Effect of remdesivir vs standard care on clinical status at 11 days in Patients with moderate COVID-19: a randomized clinical trial. JAMA. 2020;324:1048-57.

56. Beigel JH, Tomashek KM, Dodd LE, et al. Remdesivir for the treatment of Covid-19-final report. N Engl J Med. 2020;383:1813-26.

57. Goldman JD, Lye DCB, Hui DS, et al. Remdesivir for 5 or 10 days in patients with severe Covid-19. N Engl J Med. 2020;383:1827-37.
58. WHO Sollidarity Trial Consortium. Repurposed antiviral drugs for Covid-19-interim WHO solidarity trial results. N Engl J Med. 2021;384:497-511.

59. Kalil AC, Patterson TF, Mehta AK, et al. Baricitinib plus remdesivir for hospitalized adults with Covid19. N Engl J Med. 2021;384:795-807.

60. Tomazini BM, Maia IS, Cavalcanti AB, et al. Effect of dexamethasone on days alive and ventilator-free in patients with moderate or severe acute respiratory distress syndrome and COVID-19: the CoDEX randomized clinical trial. JAMA. 2020;324:1307-16.

61. RECOVERY Collaborative Group. Dexamethasone in hospitalized patients with Covid-19. N Engl J Med. 2021;384:693-704.

62. Dequin PF, Heming N, Meziani F, et al. Effect of hydrocortisone on 21-day mortality or respiratory support among critically ill patients with COVID19: a randomized clinical trial. JAMA. 2020;324: 1298-306.

63. Angus DC, Derde L, Al-Beidh F, et al. Effect of hydrocortisone on mortality and organ support in patients with severe COVID-19: the REMAP-CAP COVID-19 corticosteroid domain randomized clinical trial. JAMA. 2020;324:1317-29.

64. Jeronimo CMP, Farias MEL, Val FFA, et al. Methylprednisolone as adjunctive therapy for patients hospitalized with coronavirus disease 2019 (COVID-19; metcovid): a randomized, doubleblind, phase IIb placebo-controlled trial. Clin Infect Dis. 2020;2019:373-81.

65. Edalatifard $M$, Akhtari $M$, Salehi $M$, et al. Intravenous methylprednisolone pulse as a treatment for hospitalised severe COVID-19 patients: Results from a randomised controlled clinical trial. Eur Respir J. 2020;56:2002808.

66. Corral-Gudino L, Bahamonde A, Arnaiz-Revillas F, et al. Methylprednisolone in adults hospitalized with COVID-19 pneumonia. Wien Klin Wochenschr. 2021;133:303-11.

67. Ranjbar K, Moghadami M, Mirahmadizadeh A, et al. Methylprednisolone or dexamethasone, which one is superior corticosteroid in the treatment of hospitalized COVID-19 patients: a triple-blinded randomized controlled trial. BMC Infect Dis. 2021;21: $1-8$.

68. Hermine $\mathrm{O}$, Mariette $\mathrm{X}$, Tharaux PL, Resche-Rigon M, Porcher R, Ravaud P. Effect of tocilizumab vs usual care in adults hospitalized with COVID-19 and moderate or severe pneumonia: a randomized clinical trial. JAMA Intern Med. 2021;181:32-40. 
69. Salvarani C, Dolci G, Massari M, et al. Effect of tocilizumab vs standard care on clinical worsening in patients hospitalized with COVID-19 pneumonia: a randomized clinical trial. JAMA Intern Med. 2021;181:24-31.

70. Salama C, Han J, Yau L, et al. Tocilizumab in patients hospitalized with Covid-19 pneumonia. N Engl J Med. 2021;384:20-30.

71. Stone JH, Frigault MJ, Serling-Boyd NJ, et al. Efficacy of tocilizumab in patients hospitalized with Covid-19. N Engl J Med. 2020;383:2333-44.

72. Veiga VC, Prats JAGG, Farias DLC, et al. Effect of tocilizumab on clinical outcomes at 15 days in patients with severe or critical coronavirus disease 2019: randomised controlled trial. BMJ. 2019;2021: 372 .

73. Rosas IO, Bräu N, Waters M, et al. Tocilizumab in Hospitalized Patients with Severe Covid-19 Pneumonia. N Engl J Med. 2021;384:1503-16.

74. The REMAP-CAP investigators. Interleukin-6 receptor antagonists in critically ill patients with Covid-19. N Engl J Med. 2021;384:1491-502.

75. Soin AS, Kumar K, Choudhary NS, et al. Tocilizumab plus standard care versus standard care in patients in India with moderate to severe COVID19 -associated cytokine release syndrome (COVINTOC): an open-label, multicentre, randomised, controlled, phase 3 trial. Lancet Respir Med. 2021;9: 511-21. 2600(21)00081-3.

76. RECOVERY Collaborative Group. Tocilizumab in patients admitted to hospital with COVID-19 (RECOVERY): a randomised, controlled, open-label, platform trial. Lancet. 2021;397:1637-45.
77. Food and Drug Administration. Fact sheet for healthcare providers: emergency use authorization (EUA) of bamlanivimab and etesevimab. 2021; Available at: https://www.fda.gov/media/145802/ download. Accessed 7 June 2020.

78. Li L, Zhang W, Hu Y, et al. Effect of convalescent plasma therapy on time to clinical improvement in patients with severe and life-threatening COVID19: a randomized clinical trial. JAMA. 2020;324: 460-70.

79. Balcells ME, Rojas L, Le Corre N, et al. Early versus deferred anti-SARS-CoV-2 convalescent plasma in patients admitted for COVID-19: a randomized phase II clinical trial. PLoS Med. 2021;18:1-18.

80. Agarwal A, Mukherjee A, Kumar G, Chatterjee P, Bhatnagar T, Malhotra P. Convalescent plasma in the management of moderate covid-19 in adults in India: open label phase II multicentre randomised controlled trial (PLACID Trial). BMJ. 2020;371: $1-10$.

81. Libster R, Pérez Marc G, Wappner D, et al. Early high-titer plasma therapy to prevent severe Covid19 in older adults. N Engl J Med. 2021;384:610-8.

82. Simonovich VA, Burgos Pratx LD, Scibona P, et al. A randomized trial of convalescent plasma in Covid19 severe pneumonia. N Engl J Med. 2021;384: 619-29.

83. O'Donnell MR, Grinsztejn B, Cummings MJ, et al. A randomized double-blind controlled trial of convalescent plasma in adults with severe COVID-19. J Clin Invest. 2021;160:0-28.

84. Abani O, Abbas A, Abbas F, et al. Convalescent plasma in patients admitted to hospital with COVID-19 (RECOVERY): a randomised controlled, open-label, platform trial. Lancet. 2021;19:1-11. 